\title{
Fate of spontaneous pneumothorax from middle to old age: how to overcome an irritating recurrence?
}

\author{
Seung Hyuk Nam ${ }^{1}$, Kun Woo Kim ${ }^{2}$, Sung-Whan Kim ${ }^{3}$, Si-Wook Kim ${ }^{4}$, Jong-Myeon Hong ${ }^{4}$, Dohun Kim ${ }^{4}$ \\ ${ }^{1}$ Department of Thoracic and Cardiovascular Surgery, Hanyang University Guri Hospital, Gyeonggi, Republic of Korea; ${ }^{2}$ Department of Thoracic \\ and Cardiovascular Surgery, Gachon University Gil Medical Center, Incheon, Republic of Korea; ${ }^{3}$ Department of Thoracic and Cardiovascular \\ Surgery, Kyungsang University Changwon Hospital, Changwon, Republic of Korea; ${ }^{4}$ Department of Thoracic and Cardiovascular Surgery, College \\ of Medicine, Chungbuk National University and Chungbuk National University Hospital, Cheongju, Republic of Korea \\ Contributions: (I) Conception and design: D Kim, SH Nam; (II) Administrative support: SW Kim; (III) Provision of study materials or patients: JM \\ Hong, SW Kim, D Kim; (IV) Collection and assembly of data: D Kim; (V) Data analysis and interpretation: SW Kim, KW Kim; (VI) Manuscript \\ writing: All authors; (VII) Final approval of manuscript: All authors. \\ Correspondence to: Dohun Kim, MD, PhD. Department of Thoracic and Cardiovascular Surgery, College of Medicine, Chungbuk National \\ University and Chungbuk National University Hospital, 410 Sungbong-Ro, Heungduk-Gu, Cheongju, Chungbuk, 361-763, Republic of Korea. \\ Email: mwille@chungbuk.ac.kr.
}

Background: The causes and treatment of pneumothorax in older patients are different from those in younger patients. However, studies on this topic are limited thus; pneumothorax in older patients is often inadequately managed. The purpose of this research was to investigate the characteristics of pneumothorax in patients over 45 years old, understand patterns of management and factors of recurrence, and propose reasonable guidelines for the treatment of older patients.

Methods: Of 438 consecutive patients with spontaneous pneumothorax between 2013 and 2017, 120 patients were enrolled and divided into two groups: (I) 45-64 years and (II) $\geq 65$ years. Basic demographics, treatment modality, and patterns of surgery/recurrence were described. Clinical variables were compared between groups, and risk factors of recurrence were analyzed using logistic regression.

Results: The study population was divided into group A (younger, n=61) and B (older, n=59). Chest tube drainage was the most common procedure for both groups and chemical pleurodesis was applied more often in $\mathrm{B}(27 \%$ vs. $11 \%, \mathrm{P}=0.03)$. The length of hospital stay was longer in $\mathrm{B}(8.8$ vs. 5.9 days, $\mathrm{P}<0.01)$ but complications and recurrence rate did not differ between groups $(\mathrm{P}=0.09$ and 0.93$)$. The choice of procedures in recurrent pneumothorax was different $(\mathrm{P}=0.02)$. Specifically, invasive procedures such as surgery occurred more often in A, but non-invasive procedures occurred more often in B. Multivariate analysis revealed that bullae/blebs (odds ratio=5.57) and emphysema (odds ratio=3.83) showed a positive association with recurrence whereas surgery (odds ratio=0.11) was negative.

Conclusions: Radiological findings of emphysema or bullae/blebs are risk factors for recurrence of pneumothorax in elderly patients. Surgery in selected patients is an effective method for decreasing the recurrence rate.

Keywords: Pneumothorax; the elderly; surgery; recurrence

Submitted Apr 26, 2019. Accepted for publication Sep 27, 2019.

doi: $10.21037 /$ jtd.2019.10.30

View this article at: http://dx.doi.org/10.21037/jtd.2019.10.30

(C) Journal of Thoracic Disease. All rights reserved. 


\section{Introduction}

Pneumothorax is a benign disease, but sometimes intractable and irritating due to frequent recurrence $(1,2)$. Previous studies for risk factors of recurrence have focused on younger patients, usually under 45 years old $(3,4)$. However, the age distribution of pneumothorax shows a double peak: one in younger patients and the other in the elderly group (5). The typical pneumothorax of the former peak is a primary spontaneous pneumothorax (PSP), whereas that of the latter is a usually secondary spontaneous pneumothorax (SSP) related to pulmonary disease (6). Since the causes of pneumothorax are different between the two groups, the causes of recurrence are thought to be different as well. However, there are limited studies relating to the cause of recurrence in elderly patients.

Moreover, the management of pneumothorax in older patients is not easy. In contrast, the treatment pathway of younger patients is simple. Oxygen therapy or chest tube drainage can be performed on a case-by-case basis, and surgery can be applied on recurrence. However, it is difficult to apply the same principles to older patients. In this group, cardiopulmonary function is sometimes compromised and there may be many obstacles related to treatment and surgery, in particular (7). Therefore, bedside management, such as chemical pleurodesis, is often chosen as a primary treatment for them but its superiority is not clear (8). Although guidelines have been established, the evidence is still insufficient and the treatment modality is often chosen on the basis of the clinician's own experience.

The purpose of this study was to investigate the characteristics of pneumothorax in elderly patients, find patterns of management and risk factors for recurrence, and propose reasonable treatment guidelines for older patients.

\section{Methods}

\section{Study design and population}

This is a retrospective study using the medical records of 120 patients who had undergone pneumothorax management between March 2013 and February 2017 at a university-based tertiary hospital in Cheongju, South Korea. The follow-up period lasted until June 2018. Patient eligibility criteria included the following: spontaneous pneumothorax patients over 45 years of age, diagnosed by thoracic surgery specialists (D Kim, SW Kim, JM Hong), whose pneumothorax was managed under the same policy. The exclusion criteria were as follows: (I) patients with traumatic or iatrogenic pneumothorax; (II) patients with spontaneous pneumothorax who were under 45 years old; (III) patients who were admitted to the intensive care unit or had fatal diseases, such as lung malignancy or necrotizing pneumonia, which may have confounded clinical outcomes. The study group was divided into two groups: group A (45-64 years old) and group B ( $\geq 65$ years old). As PSP in patients under 45 years old may involve a different disease entity than pneumothorax in older patients, these younger patients were excluded from the study. Therefore, patients aged 45-64 years were operationally defined as the younger group (group A) and those aged over 64 years were the older group (group B).

\section{Variables and primary outcomes}

Demographic information, including gender, age, and medical history, particularly of pneumothorax and its management, were investigated. Radiological findings were summarized from the official report of the chest computed tomography (CT) made by radiology specialists. If there was no official CT report, we omitted the patient's results, rather than obtain a de novo reading of the CT, in order to minimize selection bias. Clinical outcomes were: patient's hospital stay (duration from the time of admission to discharge), complications (from the day of admission to a month after discharge), and recurrence of pneumothorax (considered the primary outcome; defined as the redevelopment of pneumothorax that was the primary cause of re-admission and subsequently requiring management). All data were collected and compared between the two groups. This study was reviewed and approved by the Institutional Review Board (IRB) of Chungbuk National University Hospital (2018-04-005).

\section{Management of pneumothorax}

All patients were diagnosed by thoracic surgery specialists. If the pneumothorax space was minimal (less than $5 \%$ of the total hemi-thorax area), then close observation and oxygen therapy via nasal cannula were applied; alternatively, a chest tube was inserted. A 12 -French chest tube was usually selected, but a larger tube (24- or 28-French) was chosen when chemical pleurodesis seemed to be required to stop the air leak. If chest CT was not performed around the pneumothorax event, CT was checked before discharge. The patients were usually discharged 1 day after removal of the chest tube because pneumothorax sometimes re- 
develops soon after the removal of the chest tube. However, additional management strategies were considered in the following situations: (I) prolonged air leakage lasting more than 3 days; (II) a second pneumothorax occurrence during admission; and (III) large or multiple bullae discovered by radiological study. Subsequent management included wedge resection of the lung parenchyma or chemical pleurodesis. All procedures were chosen with the consideration of the patient's cardiopulmonary reservoir and medical problems.

\section{Wedge resection or chemical pleurodesis}

The indication of surgery or wedge resection were as follows; ECOG 0-2 and (I) continuous air leakage ( $>3$ days) or recurrent pneumothorax, (II) total collapse of the lung, (III) frequently recurred pneumothorax despite of chemical pleurodesis. Although they showed ECOG 3, we tried surgery in the absence of other treatment options. Chemical pleurodesis or chest tube drainage were used in a patient who refused surgery. Not all bullous or emphysematous lesions were removed but we inspected the lung under the water to decide the air leakage site, which should be cut. Even when prominent bullae were not found on chest CT, exploration of the pleura was carried out, and apical regions of the parenchyma were resected. Video-assisted thoracic surgery (VATS) was preferred over thoracotomy. The $5^{\text {th }}$ and $7^{\text {th }}$ intercostal spaces were usually chosen for VATS, but only the $7^{\text {th }}$ was selected in uniport VATS surgery. Then, the target lung parenchyma was resected with one or two mechanical staplers. All stapled regions were covered with polyglycolic acid (PGA) felt (Neoveil, Gunze Ltd, Kyoto, Japan). However, chemical pleurodesis was chosen in patients with a poor general condition or in cases with diffuse lung lesions, where it was difficult to locate the air leakage site. The chemical agent was an extract of Viscum album (Abnoba Viscum, Abnoba GmbH, Germany). Two ampules of Abnoba Viscum were injected into the chest tube, and the patients were placed in six positions (supine, prone, right and left decubitus, sitting, and Trendelenburg) for 2 hours. A repeated injection was attempted if the air leakage persisted 2 days after the procedure.

\section{Statistical analysis}

Basic clinical characteristics, including smoking history, radiological findings, methods of management, and clinical outcomes were described and analyzed. Continuous normally distributed variables were presented as mean and standard deviation, and skewed continuous variables, as median and interquartile range. Categorical variables were presented as percentages. Differences between the two groups were assessed using an independent sample $t$-test (normally distributed continuous variables), a MannWhitney test (skewed distributed continuous variables), or a chi-squared test (categorical variables). The associations between risk factors and the recurrence of pneumothorax were assessed by logistic regression analyses. Univariate analysis was first performed, and variables yielding a $\mathrm{P}$ value below 0.1 were selected for multinomial logistic regression analysis to identify risk factors for recurrence. Results are presented as odds ratios (OR) with $95 \%$ confidence intervals (CI). All statistical tests were two-tailed with a significance level set at 0.05 and were performed using Stata software version 10.0 (Stata, College Station, TX, USA).

\section{Results}

\section{Characteristics of the study population}

We encountered 438 patients with spontaneous pneumothorax during the study period. Of these, 317 patients were excluded as they did not meet the criteria, and one died suddenly a day after admission. Hence, 120 patients were included in the study. There were 61 in group A and 59 in group B. The number of men exceeded that of women in both groups. More patients in group $\mathrm{B}$ had quit smoking $(\mathrm{P}<0.04)$, had pulmonary diseases $(\mathrm{P}<0.01)$, or radiological findings of emphysema $(\mathrm{P}<0.01)$. Group A had more current smokers and individuals with a history of pneumothorax or the accompanying surgery, but these differences were not statistically significant. Other variables, included a history of pulmonary tuberculosis or radiological findings of bullae, bronchiectasis, or old tuberculosis, and were not significantly different between groups. Detailed information can be found in Table 1 .

\section{Management of current and recurrent pneumothorax}

The management of the current pneumothorax was not different between groups, except for the use of chemical pleurodesis. Most of the patients required chest tube drainage (over $93 \%$ in both groups), but chemical pleurodesis was applied more frequently in the older group ( $27 \%$ vs. $11 \%, \mathrm{P}=0.03)$. About $20 \%(\mathrm{n}=12)$ of group $\mathrm{A}$ patients required surgery for pneumothorax; the causes of surgery were continuous air leakage, recurrence, and other reasons (e.g., totally collapsed lung or large bullae). 
Table 1 Basic demographics of the pneumothorax patients

\begin{tabular}{|c|c|c|c|}
\hline Variables & $\begin{array}{c}\text { Group A } \\
\text { (45-64 years) } \\
(n=61)\end{array}$ & $\begin{array}{c}\text { Group B } \\
\begin{array}{c}(\geq 65 \text { years }) \\
(n=59)\end{array}\end{array}$ & $P$ \\
\hline \multicolumn{4}{|l|}{ Basic demographics } \\
\hline Gender & & & 0.43 \\
\hline Male & $46[75]$ & $48[81]$ & \\
\hline Female & 15 [25] & $11[19]$ & \\
\hline \multicolumn{4}{|l|}{ Smoking } \\
\hline Quit & $28[46]$ & 38 [64] & $<0.04$ \\
\hline Current & $25[41]$ & $11[19]$ & $<0.01$ \\
\hline $\begin{array}{l}\text { Pack per year, mean } \\
\text { [SD] }\end{array}$ & $13[16]$ & $14[30]$ & 0.71 \\
\hline \multicolumn{4}{|l|}{ Previous illness history } \\
\hline COPD/ILD & $7[11]$ & $20[34]$ & $<0.01$ \\
\hline Sequelae of tuberculosis & $17[28]$ & 19 [32] & 0.60 \\
\hline Pneumothorax & 15 [25] & $10[17]$ & 0.30 \\
\hline Chest tube drainage & 14 [23] & $10[17]$ & 0.41 \\
\hline Operation & $6[10]$ & $1[2]$ & 0.06 \\
\hline \multicolumn{4}{|l|}{ Radiologic findings } \\
\hline Bullae or blebs & $27[44]$ & $24[41]$ & 0.89 \\
\hline Bronchiectasis & $7[11]$ & $6[10]$ & 0.90 \\
\hline Emphysema & 22 [36] & 39 [66] & $<0.01$ \\
\hline ILD or IPF & $1[2]$ & $6[10]$ & 0.04 \\
\hline Sequelae of tuberculosis & $13[21]$ & $14[24]$ & 0.63 \\
\hline
\end{tabular}

Continuous variables are presented as means and standard deviations and categorical variables are presented as numbers and proportions. COPD, chronic obstructive pulmonary disorder; ILD, interstitial lung disease; IPF, idiopathic pulmonary fibrosis.

However, only $8 \%(n=5)$ of patients in group B underwent surgery for prolonged air leakages.

The recurrence rate was not different between groups $(\mathrm{P}=0.93)$. In the younger group, recurrences were mostly on the same side. In the older group, recurrences were not dominated by ipsilateral recurrence. The length of hospital stay was longer in group $\mathrm{B}(\mathrm{P}<0.01)$. There was a tendency for more complications in the older group, but it was not significantly different $(\mathrm{P}=0.09)$. Complications were respiratory distress and pneumonia in group $\mathrm{B}$, but only lidocaine shock during pleurodesis in group A. Interestingly management of recurrence was significantly different
Table 2 Management and clinical outcomes of pneumothorax

\begin{tabular}{|c|c|c|c|}
\hline Variables & $\begin{array}{c}\text { Group A } \\
\text { (45-64 years) } \\
(n=61)\end{array}$ & $\begin{array}{c}\text { Group B } \\
(\geq 65 \text { years) } \\
(n=59)\end{array}$ & $\mathrm{P}$ \\
\hline \multicolumn{4}{|l|}{ Current management } \\
\hline Observation & $3[5]$ & $1[2]$ & 0.33 \\
\hline Chest tube drainage & 58 [95] & 58 [98] & 0.18 \\
\hline Chemical pleurodesis & $7[11]$ & $16[27]$ & 0.03 \\
\hline Operations & 12 [20] & $5[8]$ & 0.08 \\
\hline Cause of operations & & & 0.23 \\
\hline Recurrence & $2[17]$ & $0[0]$ & \\
\hline Continuous air leakage & $7[58]$ & $5[100]$ & \\
\hline Others* & $3[25]$ & $0[0]$ & \\
\hline \multicolumn{4}{|l|}{ Clinical outcomes } \\
\hline Length of hospital stay & $5.9[4.7-7.2]$ & $8.8[7.0-70.7]$ & $<0.01$ \\
\hline Complications** & 1 [2] & $5[8]$ & 0.09 \\
\hline Recurrence & & & 0.93 \\
\hline Overall & $17[28]$ & $16[27]$ & \\
\hline Ipsilateral & $17[28]$ & 13 [22] & \\
\hline Post-pleurodesis & 2 [29] & $4[25]$ & \\
\hline Post-operative & $0[0]$ & 1 [20] & \\
\hline Management of recurrence & & & 0.02 \\
\hline Observation & $1[6]$ & $0[0]$ & \\
\hline $\begin{array}{l}\text { Chest tube drainage, } \\
\text { only }\end{array}$ & $3[18]$ & 10 [63] & \\
\hline Chemical pleurodesis & 5 [29] & $5[31]$ & \\
\hline Operations & $8[47]$ & $1[6]$ & \\
\hline
\end{tabular}

Continuous variables are presented as means and standard deviations and categorical variables are presented as numbers and proportions. *, others included total collapse, previous operation, and large bullae; **, complications included respiratory distress and pneumonia.

$(\mathrm{P}=0.02)$. A less invasive procedure (chest tube drainage; $\mathrm{n}=10,63 \%$ ) was applied more often in the older group, but invasive management (operations; $\mathrm{n}=8,47 \%$ ) was performed more often in younger patients. This information is described in Table 2.

\section{Positive and negative factors for recurrence}

The overall treatment and recurrence are summarized in 


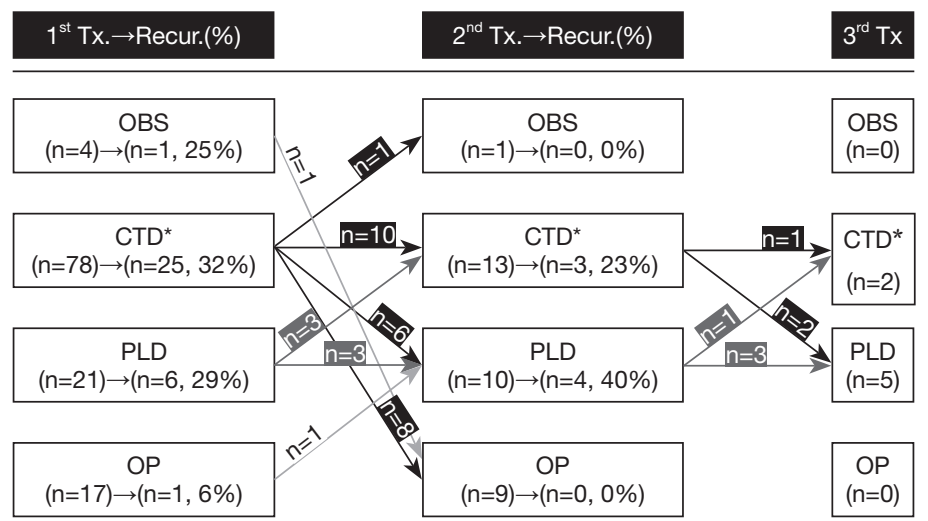

Figure 1 Flow chart of sequential treatment and recurrence for patients over 45 years old with pneumothorax. Patients who received pleurodesis suffered frequent recurrence, but those who received an operation did not. ${ }^{*}$ CTD indicates a patient who underwent chest tube drainage without pleurodesis. If the patient was managed by chest tube drainage and pleurodesis simultaneously, then he/she was defined as PLD. OP was when the patient underwent an operation regardless of previous treatment. Tx., treatment; Recur., recurrence; OBS, observation; CTD, chest tube drainage; PLD, pleurodesis; OP, operation.

the flow chart (Figure 1). In the first event of pneumothorax, $41(34 \%)$ patients were unable to resolve air leakage with chest tube alone, so chemical pleurodesis was performed in 21 patients and surgery in 17 patients. The recurrence rate was $29 \%$ in the patients with pleurodesis, but $6 \%$ in surgery. In second event of pneumothorax, 19 (58\%) patients were required more than a chest tube drainage to stop the air leakage. Of them, 10 patients underwent pleurodesis but four (40\%) recurred. On the contrary, no one recurred in nine patients who were performed surgery. In the third event of pneumothorax, five patients underwent pleurodesis, and two did chest tube drainage

To find out the positive and negative factors for recurrence, variables were analyzed by logistic regression (Table 3). Univariate analysis was performed for basic clinical characteristics, radiological findings, and various management options for current pneumothorax. Radiological findings of bullae/blebs $(\mathrm{P}<0.01)$ or emphysema $(\mathrm{P}<0.01)$ were significantly associated with recurrence. Variables of gender $(\mathrm{P}=0.05)$ and surgery $(\mathrm{P}=0.06)$ were also included in multivariate analysis, along with these two radiological features. For multivariate analysis, findings of bullae/ blebs (OR $=5.57 ; 95 \% \mathrm{CI}=2.06-15.1)$ and emphysema $(\mathrm{OR}=3.83 ; 95 \% \mathrm{CI}=1.34-10.9)$ were associated with recurrence. Moreover, surgery was negatively associated with recurrence $(\mathrm{OR}=0.11 ; 95 \% \mathrm{CI}=0.01-0.93)$.

\section{Discussion}

Management of pneumothorax in elderly patients is not easy and sometimes frustrating because they often have several diseases other than pneumothorax. This can make patients more susceptible to pneumothorax, which can sometimes be fatal because their respiratory function may be deteriorated already $(9,10)$. Moreover, the recurrence rate of SSP is higher than that of PSP (11) and the anxiety about recurrence was prominent in older patients (1). Therefore, prevention of recurrence can be more urgent in patients with SSP (10). In this study, radiological bullae/ blebs or emphysema were high-risk factors for recurrence. Moreover, although surgery was the only procedure that could decrease the recurrence rate, it was less adopted in older patients (group B).

Emphysema and bullae/blebs on preoperative chest CT were prognostic factors for recurrence in this study. Various researches have shown that emphysema is one of the major risk factors for pneumothorax (12-14), as confirmed by the present study. Goddard classification score, which is a scoring system of emphysematous lung ( $0-24$, worst as higher), could be a useful marker for deciding methods of treatment $(15,16)$. Interestingly emphysema, not bullae/blebs, was more prevalent in older groups, but the rate of recurrence was not different between the groups. This may be due to the rate of 
Table 3 Factors affecting recurrence

\begin{tabular}{|c|c|c|c|c|c|c|}
\hline Variables & \multicolumn{3}{|c|}{ Univariate } & \multicolumn{3}{|c|}{ Multivariate } \\
\hline Age & 1.00 & $0.97-1.03$ & 0.83 & & & \\
\hline Gender $^{\dagger}$ & 0.28 & $0.07-0.99$ & 0.05 & 0.71 & $0.16-3.05$ & 0.64 \\
\hline \multicolumn{7}{|l|}{ Previous history of } \\
\hline Pneumothorax & 2.01 & $0.83-5.28$ & 0.12 & & & \\
\hline Operation & 0.42 & $0.05-3.64$ & 0.43 & & & \\
\hline \multicolumn{7}{|l|}{ Smoking } \\
\hline Current & 0.66 & $0.26-1.66$ & 0.38 & & & \\
\hline Bullae/blebs $^{\dagger}$ & 5.23 & $2.14-12.8$ & $<0.01$ & 5.57 & $2.06-15.1$ & $<0.01$ \\
\hline Bronchiectasis & 2.32 & $0.71-7.51$ & 0.16 & & & \\
\hline Emphysema $^{\dagger}$ & 4.78 & $1.86-12.3$ & $<0.01$ & 3.83 & $1.34-10.9$ & 0.01 \\
\hline ILD/IPF & 1.9 & $0.40-9.00$ & 0.42 & & & \\
\hline Sequelae of tuberculosis & 1.3 & $0.51-3.27$ & 0.59 & & & \\
\hline \multicolumn{7}{|l|}{ Management } \\
\hline Observation & 0.88 & $0.09-8.72$ & 0.91 & & & \\
\hline Chest tube drainage & 0.55 & $0.09-3.47$ & 0.53 & & & \\
\hline
\end{tabular}

${ }^{\dagger}$, these factors were included in the multivariate analysis. OR, odds ratio; $\mathrm{Cl}$, confidence interval; COPD, chronic obstructive pulmonary disorder; ILD, interstitial lung disease; IPF, idiopathic pulmonary fibrosis.

current smoking, which is known to be one of the most influential factors for pneumothorax (2), and was lower among older patients. This suggests that current smoking has more influence on the recurrence of pneumothorax than the length of the smoking period.

Regardless of the type of pneumothorax, surgical management remains the most effective treatment for preventing recurrence $(17,18)$. Although surgery is still being performed via thoracotomy, and surgery with pleurectomy shows the lowest recurrence rate, less invasive surgery, such as VATS, is currently preferred $(10,19,20)$. In this study, VATS was adopted for all patients, except for one who underwent "conversion to thoracotomy" because of severe adhesion. All of the bullae or blebs were resected using a mechanical stapler, and the stapling line was covered with PGA felt. Not only surgery itself, but also newer instruments and materials, would be positive factors related to recurrence $(21,22)$.

There are some limitations to this study. First, a selection bias may have been present. Patients who underwent surgery, especially among the elderly, were highly selected. As patients with severe systemic and pulmonary problems could not undergo single lung ventilation under general anesthesia, surgical patients were more likely to be relatively healthy. Second, this research was not a randomized prospective study, and thus some pneumothorax patients who had serious or fatal medical conditions other than pneumothorax would be excluded. Therefore, the patient population in this study should be regarded as a relatively healthy population. Despite these limitations, this study 
is important in that it examined the factors predicting the recurrence of pneumothorax in middle-aged or older patients and suggested a method to decrease the recurrence rate. Moreover, this paper suggests that surgery for pneumothorax should be encouraged regardless of age if the indications are met.

In summary, radiological findings of emphysema or bullae/blebs are risk factors for recurrence of pneumothorax in middle-aged or older patients. Surgery in highly selected patients may be an effective method for decreasing the recurrence rate. Further studies are required to identify the surgical indications accurately.

\section{Acknowledgments}

Funding: This research was supported by Basic Science Research Program through the National Research Foundation of Korea (NRF) funded by the Ministry of Science, ICT \& Future Planning (2017R1C1B5015969).

\section{Footnote}

Conflicts of Interest: The authors have no conflicts of interest to declare.

Ethical Statement: The authors are accountable for all aspects of the work in ensuring that questions related to the accuracy or integrity of any part of the work are appropriately investigated and resolved. This study was reviewed and approved by the Institutional Review Board (IRB) of Chungbuk National University Hospital (2018-04-005).

\section{References}

1. Kim D, Shin HJ, Kim SW, et al. Psychological Problems of Pneumothorax According to Resilience, Stress, and Post-Traumatic Stress. Psychiatry Investig 2017;14:795800.

2. Walker SP, Bibby AC, Halford P, et al. Recurrence rates in primary spontaneous pneumothorax: a systematic review and meta-analysis. Eur Respir J 2018. doi: 10.1183/13993003.00864-2018.

3. Imperatori A, Rotolo N, Spagnoletti M, et al. Risk factors for postoperative recurrence of spontaneous pneumothorax treated by video-assisted thoracoscopic surgerydagger. Interact Cardiovasc Thorac Surg 2015;20:647-51; discussion 651-2.

4. Steger V, Sostheim U, Leistner M, et al. Recurrence of Spontaneous Pneumothorax Is Not Associated with Allegedly Risk-Prone Lifestyle Conduct. Ann Thorac Cardiovasc Surg 2018;24:25-31.

5. Gupta D, Hansell A, Nichols T, et al. Epidemiology of pneumothorax in England. Thorax 2000;55:666-71.

6. American Lung Association, Epidemiology and Statistics Unit, Research and Health Education Division. Trends in COPD (Chronic Bronchitis and Emphysema): Morbidity and Mortality. 2013.

7. Bintcliffe OJ, Hallifax RJ, Edey A, et al. Spontaneous pneumothorax: time to rethink management? Lancet Respir Med 2015;3:578-88.

8. Adewole OO, De Keukeleire T, Phillips AS, et al. Effectiveness of thoracoscopic talc pleurodesis in the management of complicated spontaneous pneumothorax. J Bronchology Interv Pulmonol 2015;22:48-51.

9. Noppen M, De Keukeleire T. Pneumothorax. Respiration 2008;76:121-7.

10. MacDuff A, Arnold A, Harvey J, et al. Management of spontaneous pneumothorax: British Thoracic Society Pleural Disease Guideline 2010. Thorax 2010;65 Suppl 2:ii18-31.

11. Guo Y, Xie C, Rodriguez RM, et al. Factors related to recurrence of spontaneous pneumothorax. Respirology 2005;10:378-84.

12. Hiraki T, Mimura H, Gobara H, et al. Incidence of and risk factors for pneumothorax and chest tube placement after CT fluoroscopy-guided percutaneous lung biopsy: retrospective analysis of the procedures conducted over a 9-year period. AJR Am J Roentgenol 2010;194:809-14.

13. Hobbs BD, Foreman MG, Bowler R, et al. Pneumothorax risk factors in smokers with and without chronic obstructive pulmonary disease. Ann Am Thorac Soc 2014;11:1387-94.

14. Nour-Eldin NE, Alsubhi M, Emam A, et al. Pneumothorax Complicating Coaxial and Non-coaxial CT-Guided Lung Biopsy: Comparative Analysis of Determining Risk Factors and Management of Pneumothorax in a Retrospective Review of 650 Patients. Cardiovasc Intervent Radiol 2016;39:261-70.

15. Isaka M, Asai K, Urabe N. Surgery for secondary spontaneous pneumothorax: risk factors for recurrence and morbidity. Interact Cardiovasc Thorac Surg 2013;17:247-52.

16. Sevinc S, Kaya SO, Akcam TI, et al. Prolonged air leakage in secondary spontaneous pneumothorax: is proportion of emphysema important? Clin Respir J 2017;11:833-8.

17. Jeon HW, Kim YD, Choi SY, et al. When Is the Optimal 
Timing of the Surgical Treatment for Secondary Spontaneous Pneumothorax? Thorac Cardiovasc Surg 2017;65:50-5.

18. Baumann MH, Strange C, Heffner JE, et al. Management of spontaneous pneumothorax: an American College of Chest Physicians Delphi consensus statement. Chest 2001;119:590-602.

19. Tschopp JM, Rami-Porta R, Noppen M, et al. Management of spontaneous pneumothorax: state of the art. Eur Respir J 2006;28:637-50.

20. Matsuoka K, Kuroda A, Kang A, et al. Surgical results

Cite this article as: Nam SH, Kim KW, Kim SW, Kim SW, Hong JM, Kim D. Fate of spontaneous pneumothorax from middle to old age: how to overcome an irritating recurrence? J Thorac Dis 2019;11(11):4782-4789. doi: 10.21037/jtd.2019.10.30 of video-assisted thoracic surgery and risk factors for prolonged hospitalization for secondary pneumothorax in elderly patients. Ann Thorac Cardiovasc Surg 2013;19:18-23.

21. Lee S, Kim HR, Cho S, et al. Staple line coverage after bullectomy for primary spontaneous pneumothorax: a randomized trial. Ann Thorac Surg 2014;98:2005-11.

22. Kim SW, Kim D. Management of long-term persistent air leakage developed after bullectomy for giant bullous lung disease associated with neurofibromatosis type 1 . J Thorac Dis 2016;8:E140-3. 